\title{
Insulin and hypoxia-inducible factor- 1 cooperate in pancreatic cancer cells to increase cell viability
}

\author{
DAPENG ZHANG ${ }^{1}$, LIHUA CUI ${ }^{1}$, SHU SHUN LI $^{2,4}$ and FENG WANG ${ }^{1,3}$ \\ ${ }^{1}$ Principal Investigator Unit, Tianjin Institute of Integrative Medicines for Acute Abdominal Diseases, \\ Nankai Hospital, Tianjin 300100, P.R. China; Departments of ${ }^{2}$ Clinical Immunology and \\ ${ }^{3}$ Surgery, Karolinska University Huddinge Hospital, Huddinge SE-14186, Sweden
}

Received September 19, 2014; Accepted May 20, 2015

DOI: $10.3892 / \mathrm{ol} .2015 .3384$

\begin{abstract}
The aim of the present study was to investigate whether interstitial insulin and cancer-induced hypoxia-inducible factor-1 (HIF-1) cooperate in pancreatic cancer cells. A population of 45 nude mice were divided into one intact control group and six pancreatic tumor-carrier groups. Pancreatic tumors were generated using HIF-1-positive wild-type MiaPaCa2 (wt-MiaPaCa2) pancreatic cancer cells in three groups of carriers and $\mathrm{MiaPaCa} 2$ cells transfected with small interfering RNA against HIF-1 $\alpha$ (si-MiaPaCa2 cells) in the other three carrier groups. To vary the intrapancreatic insulin levels, tumor-carrying mice were subjected to one of the following conditions: i) Untreated, ii) single injection of the $\beta$-cell toxin streptozotosin prior to cancer cell transplantation and iii) daily injection of insulin following cancer cell transplantation. After 12 weeks, tumor viability was assessed by histological analysis. Western blotting of the tumor grafts was performed to determine the protein expression levels of insulin receptor (IR) and two downstream proteins, hexokinase-II (HK-II) and vascular endothelial growth factor (VEGF). Histologically, the greatest viability was observed in wt-MiaPaCa2 tumors with carriers that remained untreated. These tumors also exhibited greater IR expression than their si-MiaPaCa 2 counterparts, indicating that HIF-1 is necessary for basal expression of IR. However, IR expression was increased in wt-MiaPaCa2 and si-MiaPaCa2 tumors when the carriers were treated with exogenous insulin. This indicates that the insulin-induced IR expression was independent
\end{abstract}

Correspondence to: Professor Feng Wang, Principal Investigator Unit, Tianjin Institute of Integrative Medicines for Acute Abdominal Diseases, Nankai Hospital, 6 Changjiang Road, Tianjin 300100, P.R. China

E-mail: fengwf@aim.com

Present address: ${ }^{4}$ Department of Microbiology, Immunology and Infectious Diseases, Cumming School of Medicine, University of Calgary, 3280 Hospital Drive, Alberta, Canada

Key words: pancreatic cancer, insulin, hypoxia-inducible factor-1 $\alpha$, nude mouse of HIF-1. Notably, the insulin-induced IR expression was associated with increased HK-II and VEGF expression in wt-MiaPaCa2 tumors but not si-MiaPaC2 tumors. Therefore, the present study proposes that insulin and HIF-1 may cooperate to increase pancreatic cancer cell viability. Furthermore, the HIF-1 signaling pathway is required for insulin-induced HK-II and VEGF expression, as well as basal IR expression levels in pancreatic cancer cells.

\section{Introduction}

Transcription factor hypoxia-inducible factor-1 (HIF-1) is composed of $\alpha$ and $\beta$ subunits (1). When mammalian cells contain sufficient oxygen, HIF-1 $\alpha$ is degraded by proteasomes. Thus, under normal conditions, mammalian cells contain HIF-1 $\beta$, but not HIF-1 $\alpha$ (2). However, in hypoxic conditions, HIF-1 $\alpha$ stabilizes and associates with HIF-1 $\beta$. The resulting HIF-1 complex regulates target genes that encode growth and angiogenic factors, such as vascular endothelial growth factor (VEGF), glycolysis enzymes [for example, hexokinase (HK)] and glucose transporters (3). Therefore, HIF-1 expression increases the viability of hypoxic cells and the rate of glycolysis.

Intratumoral hypoxia develops in malignant tumors, including pancreatic cancer (4). A hypoxic environment increases HIF-1 $\alpha$ stability and induces its expression in cancer cells $(5,6)$. Subsequently, HIF-1 $\alpha$ expression in cancer cells leads to an increase in cell growth and migration, glycolytic activity, and angiogenesis $(3,7,8)$.

Healthy cells produce energy by oxidative phosphorylation (OXPHOS) in the mitochondria. However, OXPHOS is inhibited in the majority of cancer cells, which instead derive the preponderance of their energy from an increase in the rate of glycolysis (9). Glycolysis is an inefficient method of cellular energy production; therefore, cancer cells increase the expression levels of glucose transporters and glycolytic enzymes to maintain a high rate of glycolysis (10). This is known as the Warburg effect. HIF-1 $\alpha$ makes a significant contribution to the Warburg effect by enhancing the expression of glucose transporters and glycolytic enzymes. Furthermore, HIF-1 $\alpha$ expression increases the growth, migration and angiogenesis of cancer cells $(3,7,8)$.

Endocrine and exocrine pancreatic tissues are separated by a permeable membrane, thus, insulin secreted from 
endocrine $\beta$-cells diffuses into the pancreatic interstitium at high concentrations (11). When pancreatic cancer occurs, intrapancreatic insulin activates insulin receptors (IRs) expressed on cancer cells, and induces cell growth, migration and angiogenesis (12-15). Notably, IR activation and HIF-1 $\alpha$ expression have the same effect on pancreatic cancer cell growth, migration and angiogenesis. In consideration of this, we hypothesize that the IR and HIF-1 signaling pathways interact with each other in pancreatic cancer cells. In agreement with this hypothesis, intracellular kinases, such as phosphoinositide 3-kinase, Akt and extracellular signal-regulated kinases $1 / 2$, are involved in the signaling cascades that induce HIF-1 $\alpha$ expression and those that follow IR activation $(6,12,13)$.

The present study investigated whether the insulin and HIF-1 signaling pathways cooperate in pancreatic cancer cells. Wild-type MiaPaCa2 cells (wt-MiaPaCa2) and $\mathrm{MiaPaCa} 2$ cells transfected with small interfering RNA against HIF-1 $\alpha$ (si-MiaPaCa2) were orthotopically transplanted into separate nude mice. In our previous studies, it was demonstrated that $\mathrm{wt}-\mathrm{MiaPaCa} 2$ cells expressed HIF-1 $\alpha$ when cultured in vitro under hypoxic conditions and when grown as tumor grafts in nude mice. By contrast, si-MiaPaCa2 cells did not express HIF-1 $\alpha$ in the aforementioned conditions (7). The present study varied intrapancreatic insulin levels in tumor-carrying mice under the following conditions: i) Untreated (mice $\left.{ }_{u n}\right)$; ii) single injection of the $\beta$-cell toxin streptozotosin (SZ) prior to cancer cell transplantation $\left(\right.$ mice $\left._{\mathrm{sz}}\right)$ and iii) daily injection of insulin following cancer cell transplantation $\left(\right.$ mice $_{i n}$ ). By altering levels of insulin in these mice, the current study aimed to investigate possible cooperation between interstitial insulin and cancer-induced HIF-1 expression.

\section{Materials and methods}

Animal experiments. The wt-MiaPaCa2 pancreaticcancercells were purchased from the American Type Culture Collection (Rockville, MD, USA). The si-MiaPaCa2 cell line was created in our previous study (7), and the growth, glycolysis and migration of the two cell types were characterized in our previous studies $(7,16,17)$. Mice were handled following the principles of laboratory animal care described by the National Institutes of Health (grants1.nih.gov/grants/olaw/references/phspol.htm). Following acclimation, 45 male nude mice (age, 5 weeks; weight, $23 \pm 5 \mathrm{~g}$; Taconic, Ry, Denmark) were randomly designated to one intact control group and six tumor carrier groups (Table I). The control mice ( mice $_{\text {ctr }}, \mathrm{n}=5$ ) were left untreated, the wt-MiaPaCa2 cells were orthotopically transplanted into three groups of nude mice (mice un-wt $_{1}, \mathrm{n}=6 ;$ mice $_{\text {in-wt }}, \mathrm{n}=7$; and mice $_{\mathrm{sz}-\mathrm{wt}}, \mathrm{n}=7$ ) and the si-MiaPaCa2 cells were orthotopically transplanted into the remaining three groups of nude mice (mice $_{\text {un-si }}, \mathrm{n}=6 ;$ mice $_{\mathrm{in}-\mathrm{si}}, \mathrm{n}=7$; and mice $_{\mathrm{sz}-\mathrm{si}}, \mathrm{n}=7$ ), as previously described (7). All tumor carriers were subjected to one of the following three conditions: i) $\mathrm{Mice}_{\text {un-wt }}$ and mice un-si $_{\text {un }}$ were untreated; ii) following cancer cell transplantation, $50 \mathrm{mU}$ insulin (Novo Nordisk, Bagsværd, Denmark) was subcutaneously (s.c.) injected into mice $_{\text {in-wt }}$ and mice $_{\text {in-si }}$ once a day; and iii) one day prior to cancer-cell transplantation, SZ (cat no. S0130; Sigma Aldrich, St. Louis, MO, USA) was
Table I. Groups of nude mice $(\mathrm{n}=7)$.

\begin{tabular}{|c|c|c|c|}
\hline Groups & $\mathrm{n}$ & Transplanted cells & Treatment $^{\mathrm{a}}$ \\
\hline mice $_{\text {ctr }}$ & 5 & None & NA \\
\hline mice $_{\text {un-wt }}$ & 6 & wt-MiaPaCa2 & None \\
\hline mice $_{\text {in-wt }}$ & 7 & wt-MiaPaCa2 & $\begin{array}{l}\text { Insulin injection } \\
\text { following cancer } \\
\text { induction }\end{array}$ \\
\hline mice $_{\mathrm{sz}-\mathrm{wt}}$ & 7 & wt-MiaPaCa2 & $\begin{array}{l}\text { SZ injection prior to } \\
\text { cancer induction }\end{array}$ \\
\hline mice $_{\text {un-si }}$ & 6 & si-MiaPaCa2 & None \\
\hline mice $_{\text {in-si }}$ & 7 & si-MiaPaCa2 & $\begin{array}{l}\text { Insulin injection } \\
\text { following cancer } \\
\text { induction }\end{array}$ \\
\hline mice $_{\mathrm{sz}-\mathrm{si}}$ & 7 & si-MiaPaCa2 & $\begin{array}{l}\text { SZ injection prior to } \\
\text { cancer induction }\end{array}$ \\
\hline
\end{tabular}

an addition to cancer induction. Ctr, control; un, untreated; wt, wild-type; in, insulin; sz, streptozosin; si, small interfering RNA.

s.c. injected into mice $_{\mathrm{sz}-\mathrm{wt}}$ and mice $\mathrm{sz}_{\mathrm{sz}}$ at a dose of $50 \mathrm{mg} / \mathrm{kg}$. This dose was derived from a pilot study wherein different doses of SZ (20-240 mg $/ \mathrm{kg})$ were administered to nude mice carrying wt-MiaPaCa2 cells. The aim of the pilot study was to determine the maximum possible dose of SZ that allowed the tumor carriers to survive for 12 weeks. Notably, the selected SZ dose $(50 \mathrm{mg} / \mathrm{kg})$ was considerably smaller than that used to induce diabetes in normal nude mice $(240 \mathrm{mg} / \mathrm{kg})(18)$. In addition, all 45 mice survived treatment. The mice were sacrificed under anesthesia $(50 \mathrm{mg}$ pentobarbital $/ \mathrm{kg}$, intraperitoneally), and the chest and abdomen were opened by incision. The heart was punctured using a needle (gauge \#18) connected to a syringe. Blood was collected in the syringe, and the plasma was separated. Furthermore, healthy pancreas and tumor biopsies were obtained, and stored at $-80^{\circ} \mathrm{C}$.

Assays. Insulin and c-peptide were extracted from tumor-free pancreatic tissue using acid ethanol, as previously described (19). Pancreatic insulin and c-peptide concentrations were determined using radioimmunoassay kits (Linco Research Inc., St. Charles, MO, USA). Plasma insulin and c-peptide concentrations were determined using the same kits, however, plasma glucose and lactate were measured in a biochemical analyzer (2700; YSI, Inc., Yellow Springs, OH, USA). Cryosections were prepared from the tumor biopsies (8- $\mu \mathrm{m}$ thick) using a microtome cryostat (CM1950; Leica Microsystems GmbH, Wetzlar, Germany). Subsequently, apoptosis was stained by terminal deoxynucleotidyl transferase dUTP nick end labeling using an ApopTag ${ }^{\circledR}$ kit (EMD Millipore, Temecula, CA, USA) (20) and the sections were counterstained with hematoxylin. Microscopic morphology was captured region-by-region with a DM4000B microscope (Leica Microsystems GmbH) using a charge-coupled device camera (DFC500; Leica Camera AG). Images were merged using Leica Application Suite software version 3.8 (Leica Microsystems $\mathrm{GmbH}$ ) and a global view was reconstituted for each section. Western 
A

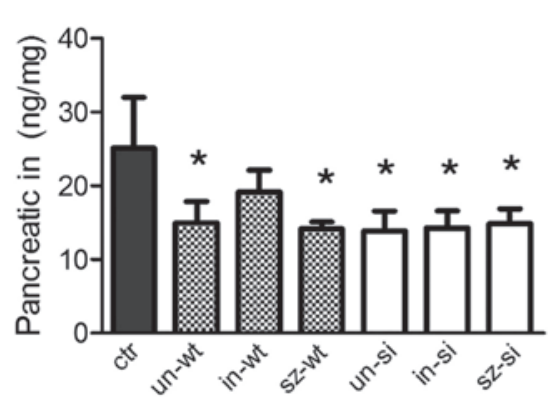

C

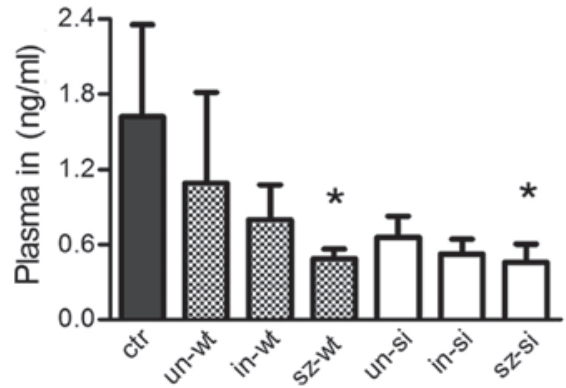

E

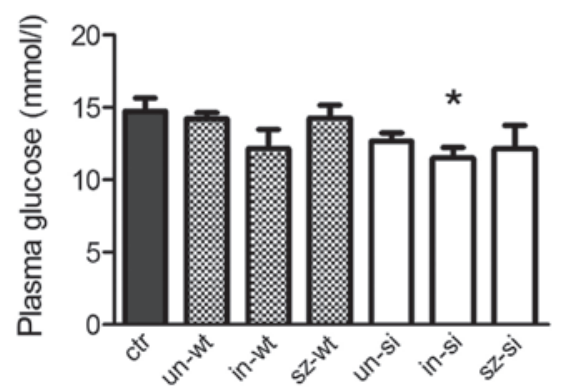

B

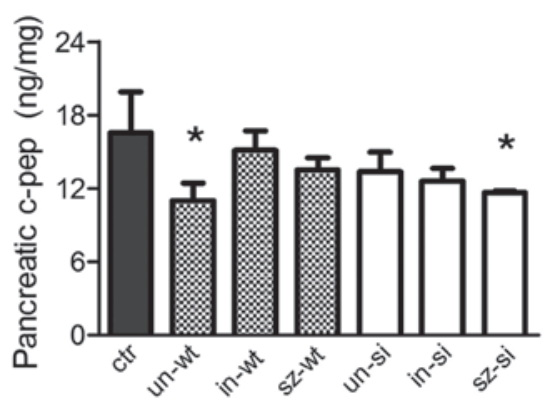

D

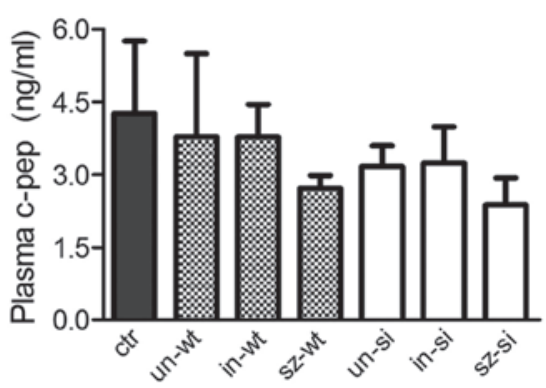

$\mathbf{F}$

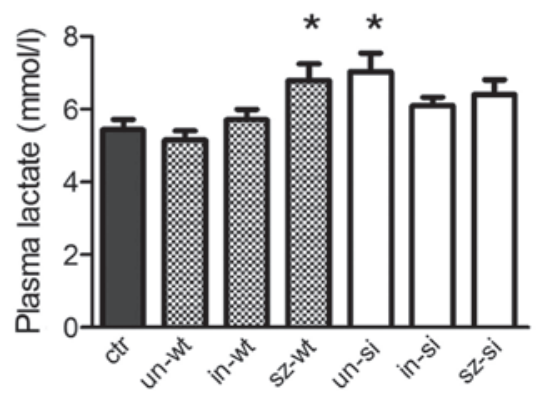

Figure 1. Nude mice $(n=45)$ were designated to mice ${ }_{\text {ctr }}$ and six pancreatic tumor carrier groups. In three groups (mice ${ }_{u n-w t}$, mice ${ }_{\text {in-wt }}$ and mice $\left.{ }_{\mathrm{sz}-\mathrm{wt}}\right)$, pancreatic tumors were composed of wt-MiaPaCa2 pancreatic cancer cells. In the other carriers (mice un-si, $_{\text {, }}$ mice $_{\text {in-si }}$ and mice ${ }_{\text {sz-si }}$ ), tumors were composed of

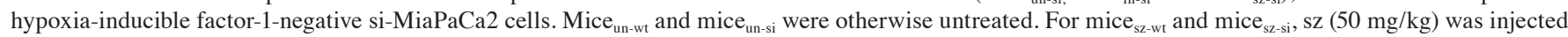

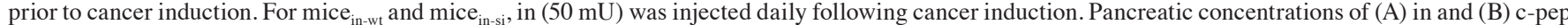
were determined, and the results were normalized to the weight of the samples (in mg). Plasma samples were analyzed for (C) in, (D) c-pep, (E) glucose and (F) lactate concentrations levels. Error bars indicate the standard error of the mean. ${ }^{*} \mathrm{P}<0.05$ vs. mice ctr . Ctr, control; un, untreated; wt, wild-type; in, insulin; sz, streptozosin; si, small interfering RNA; c-pep, c-peptide.

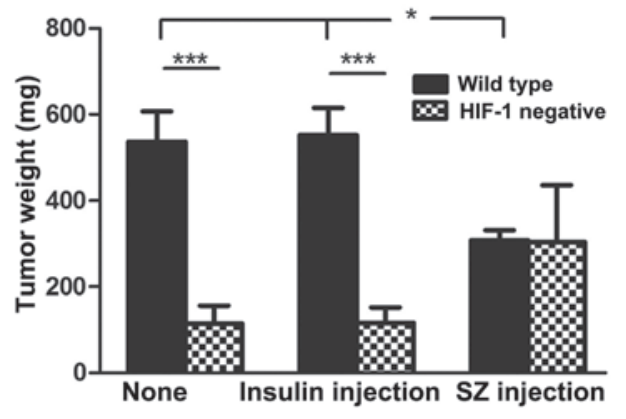

Figure 2. Weight of tumor grafts in six groups of mice transplanted with HIF-1 positive wild-type or HIF-1 small interfering RNA MiaPaCa2 pancreatic cancer cells. Error bars indicate the standard error of the mean. ${ }^{*} \mathrm{P}<0.05$, ${ }^{* * * *} \mathrm{P}<0.001$. HIF-1, hypoxia-inducible factor-1; SZ, streptozosin.

blotting was used to determine the protein expression levels of IR, HK-II, and VEGF in the tumor grafts $(7,16,17,20)$. Briefly, whole-cell protein was extracted following homogenization of the tumor grafts. Proteins were separated on an $8 \%$ SDS gel and transferred to polyvinylidene difluoride membranes. The membranes were then incubated overnight at $4^{\circ} \mathrm{C}$ with monoclonal mouse anti-human IR- $\beta(1: 1,000$; cat no. 69508; Abcam, Cambridge, UK), monoclonal mouse anti-human VEGF (1:1,000; cat no. 555036; BD Pharmingen, San Diego, CA, USA) and polyclonal goat anti-human HK-II (1:1,000; cat no. 6521; Santa Cruz Biotechnology, Inc., Dallas, TX, USA) primary antibodies. After rinsing, membranes were incubated with the appropriate horseradish peroxidase-conjugated secondary antibodies [sheep anti-mouse IgG (1:2,000; cat no. NA931; GE Healthcare Life Sciences, Chalfont, UK) and polyclonal rabbit anti-goat $\operatorname{IgG}(1: 2,000$; cat no. AP106P; EMD Millipore)] for $1 \mathrm{~h}$ at room temperature and treated with chemiluminescence detection reagents. Specific blotting was recorded using an image analysis system (ChemiDoc ${ }^{\mathrm{TM}}$ XRS System, Bio-Rad Laboratories, Inc., Hercules, CA, USA).

Statistical analysis. Analyses were performed using SPSS software version 17.0 (SPSS, Inc., Chicago, IL, USA). Data are presented as the mean \pm standard error of the mean. When three or more groups were involved, results were analyzed using analysis of variance. However, when fewer than three groups were involved, Student's t-test was performed. 
A

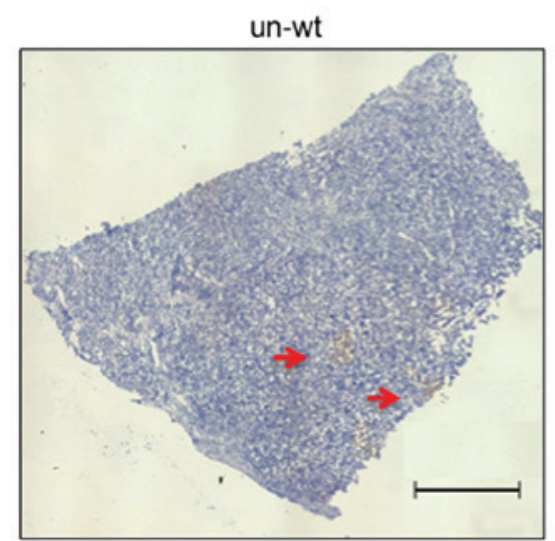

C

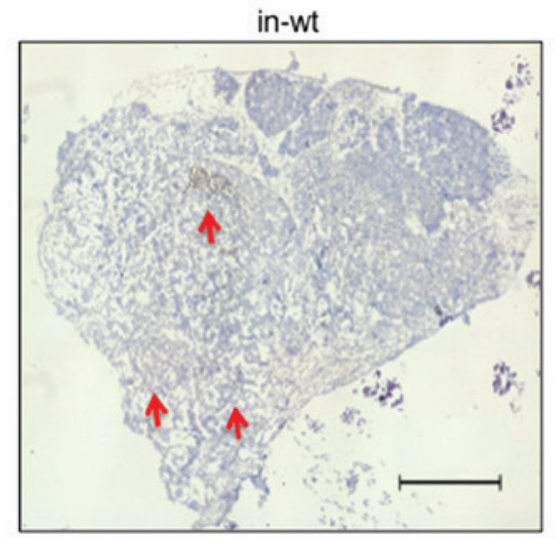

$\mathbf{E}$

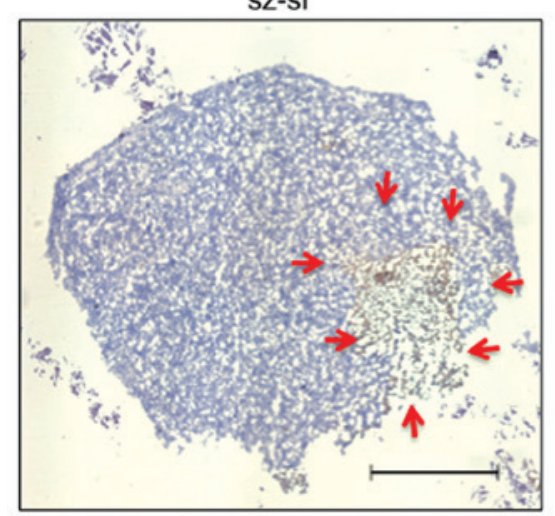

B

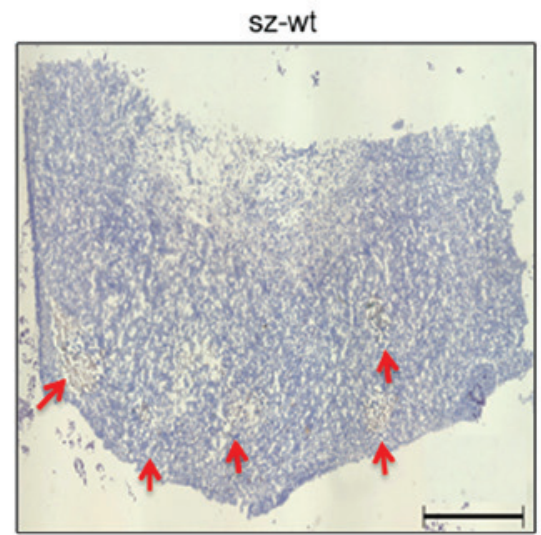

D

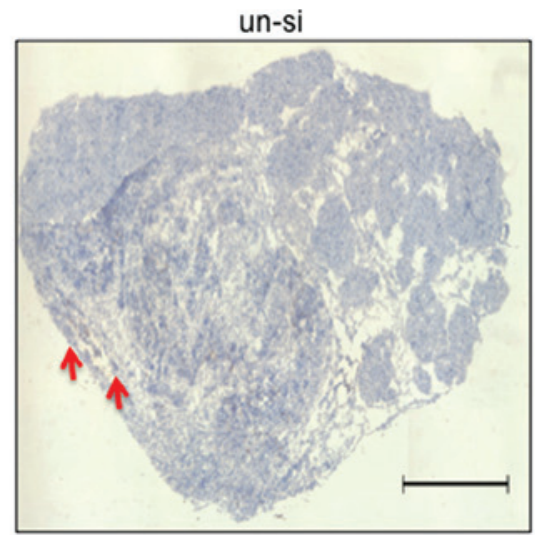

F

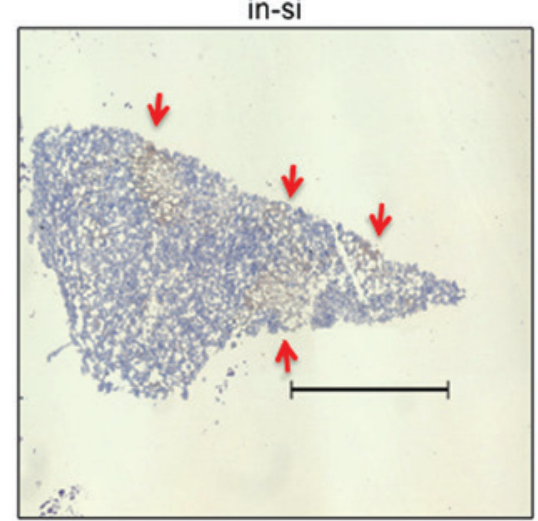

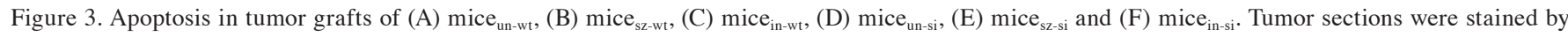
terminal deoxynucleotidyl transferase dUTP nick end labeling, and hematoxylin staining. Apoptotic cells are stained in brown and indicated by arrows. The six panels are representative of the six experimental groups. Scale bar, $1 \mathrm{~mm}$. un, untreated; wt, wild-type; sz, streptozotosin; in, insulin; si, small interfering RNA.

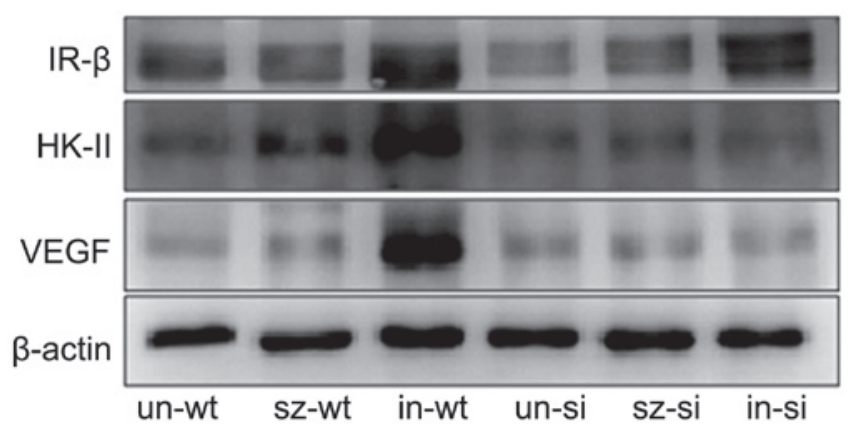

Figure 4. Western blot indicating the expression of IR- $\beta$, HK-II and VEGF in tumors from different nude mice groups. $\beta$-actin was used as the loading control. IR- $\beta$, insulin receptor- $\beta$; HK-II, hexokinase-II; VEGF, vascular endothelial growth factor; un, untreated; wt, wild-type; sz, streptozotosin; in, insulin; si, small interfering RNA.
$\mathrm{P}<0.05$ was considered to indicate a statistically significant difference.

\section{Results}

Pancreatic insulin concentration significantly decreased in five out of six groups of tumor carriers compared with the mice $_{\text {ctr }}(\mathrm{P}<0.05$; Fig. 1A). Furthermore, pancreatic c-peptide concentration significantly decreased in mice $_{\text {un-wt }}$ and mice $_{\mathrm{sz}-\mathrm{si}}(\mathrm{P}<0.05$; Fig. 1B), and plasma insulin concentration levels were significantly decreased in mice ${ }_{\mathrm{sz}-\mathrm{wt}}$ and mice $\mathrm{sz}_{\mathrm{sz}}$ $\left(\mathrm{P}<0.05\right.$; Fig. 1C) compared with mice ${ }_{\text {ctr }}$. No tumor carriers exhibited significant changes in plasma c-peptide concentration (Fig. 1D). However, plasma glucose concentration 
significantly decreased in mice $_{\text {in-si }}(\mathrm{P}<0.05$; Fig. 1E), and plasma lactate concentration significantly increased in mice $\mathrm{sz}_{\mathrm{wt}}$ and mice $_{\text {un-si }}(\mathrm{P}<0.05 ;$ Fig. 1F) compared with mice ctr .

wt-MiaPaCa2 tumors from mice un-wt $_{\text {and }}$ mice ${ }_{\text {in-wt }}$ were heavier than their si-MiaPaCa2 counterparts from mice $_{\text {un-si }}$ and mice $_{\text {in-si }}(\mathrm{P}<0.001)$, as well as those from mice ${ }_{\mathrm{sz}-\mathrm{wt}}(\mathrm{P}<0.05 ;$ Fig. 2$)$. However,nosignificantdifferencesintumorweightwereobserved between the three groups of si-MiaPaCa2 tumors (Fig. 2). All tumor sections contained apoptotic regions (Fig. 3). Tumors from mice ${ }_{\text {un-wt }}$ exhibited the greatest cell viability, with only small and sporadic necrotic regions (Fig. 3A). By contrast, large, central necrosis was observed in wt-MiaPaCa2 tumors in carriers treated with SZ. In this group, the large, central necrotic regions were surrounded by smaller necrotic regions (Fig. 3B). The third group of wt-MiaPaCa2 tumors from mice ${ }_{\text {in-wt }}$ exhibited a loose organization that appeared to be the result of chronic cell death (Fig. 3C). Thus, wt-MiaPaCa2 tumors in carriers treated with $\mathrm{SZ}$ or insulin exhibited poorer cell viability than the wt-MiaPaCa2 tumors in which the carriers were untreated. This indicates that intact interstitial insulin concentration is the most favorable condition for cancer cell survival. However, examination of si-MiaPaCa2 tumors always revealed poor cell viability. For example, tumors from mice un-si $_{\text {were largely }}$ composed of hollow regions (Fig. 3D). However, a high rate of apoptosis was observed in tumors from mice sz-si $_{1}$, even in peripheral regions (Fig. 3E). Additionally, si-MiaPaCa2 tumors from mice $_{\text {in-si }}$ contained numerous apoptotic regions despite their small size (Fig. 3F).

Protein expression analysis of IR and associated proteins identified lower IR expression in si-MiaPaCa2 tumors from mice $_{\text {un-si }}$ than their wt-MiaPaCa2 counterparts (Fig. 4). This indicates that HIF-1 is required for basal IR expression. Insulin

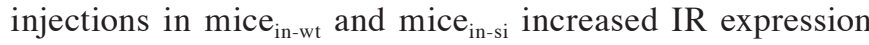
levels in tumors from these carriers (Fig. 4). Thus, insulin treatment markedly increased the expression of IR in cancer cells, independent of HIF-1 expression. Although exogenous insulin induced similar increases in IR expression in wt- and si-MiaPaCa2 cancer cells in vivo, this effect was associated with increased HK-II and VEGF protein expression in wt-MiaPaCa2 tumors but not si-MiaPaCa2 tumors (Fig. 4). Thus, cancer-induced HIF-1 expression appears to be necessary for insulin to increase HK-II and VEGF expression in the same cancer cells.

\section{Discussion}

Carcinogen-induced pancreatic cancer is associated with a decrease in the population of pancreatic $\beta$-cells in hamsters (21). This raises the possibility that the presence of pancreatic cancer may cause a decrease in pancreatic insulin production, thus resulting in decreased levels of insulin in the pancreatic interstitial fluid. In the present study, five out of six tumor carrier groups exhibited a decrease in intrapancreatic insulin concentration. Furthermore, a significant decrease in plasma insulin was observed in the mice that were treated by the $\beta$-cell toxin SZ. Therefore, in addition to the tumor-induced decrease in pancreatic insulin concentration, SZ treatment may further decrease interstitial insulin levels in the pancreas.

The Warburg effect increases glucose consumption and lactate production in cancer cells. Following the transport of cancer-induced lactate to the liver and its subsequent conversion to glucose, it re-enters the bloodstream and can be returned back to cancer cells. The glucose-lactate cycle increases energy expenditure and causes cancer cachexia $(22,23)$. In the present study, certain tumor-carrying mice exhibited decreased glucose levels and increased lactate levels in the plasma. These results may be a consequence of increased glucose turnover in the animals.

Tumors from mice ${ }_{\text {un-si }}$ exhibited lower levels of IR expression than their wild-type counterparts, indicating that the HIF-1 signaling pathway is required for the maintenance of basal IR levels in pancreatic cancer cells. Significantly, IR expression was increased in tumors from insulin-treated mice $_{\text {in-wt }}$ and mice ${ }_{\text {in-si }}$, thus, the insulin-induced IR expression was independent of HIF-1 expression. However, an increase in VEGF and HK-II protein expression levels, induced by exogenous insulin, was only observed in tumors from mice in-wt $_{\text {int }}$ but not mice $_{\text {in-si }}$. This indicates that although insulin-induced IR expression is independent of HIF-1, HIF-1 is still required for insulin to increase HK-II and VEGF expression levels in pancreatic cancer cells.

In the present study, nude mice were treated with SZ or insulin in an attempt to alter insulin concentrations in the pancreatic interstitium. The results indicate that SZ treatment decreased interstitial insulin in the pancreas. Exogenous insulin increased IR, HK-II and VEGF expression levels in wt-MiaPaCa 2 tumors carried by mice in-wt $_{\text {, }}$, indicating that insulin treatment may stimulate tumor cells in the pancreas. However,

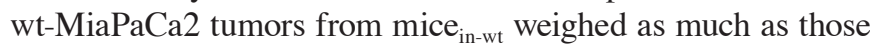
from mice $_{\text {un-wt }}$, opposing the hypothesis that exogenous insulin stimulated tumor cells in vivo. In addition, histological examination indicated that tumors from mice in-wt $_{\text {th }}$ had poor viability. Considering that exogenous insulin may decrease insulin release by negative feedback, the current data indicates that the ultimate effect of exogenous insulin on pancreatic cancer cells may be of an inhibitory nature. Notably, wt-MiaPaCa2 tumors from mice $_{\text {un-wt }}$ and mice $_{\text {in-wt }}$ were heavier than those from mice sz-wt $_{\text {. }}$. This is consistent with the hypothesis that SZ reduces the stimulation of interstitial insulin in pancreatic cancer cells. Finally, tumors from mice un-wt $_{\text {and }}$ anice ${ }_{\text {in-wt }}$ were heavier than their si-MiaPaCa 2 counterparts. This is in agreement with the results of a previous study (7), which identified that the HIF-1 signaling pathway is important for the growth of cancer cells. To the best of our knowledge, the present study is the first to investigate the effect of intra-pancreatic insulin on pancreatic cancer cells in vivo. The results are consistent with those of previous in vitro studies, which have demonstrated the stimulatory effects of insulin on pancreatic cancer cells $(14,15)$. Thus, antagonizing the activity of intra-pancreatic insulin may contribute to the inhibition of pancreatic cancer.

In conclusion, the present study demonstrated that paracrine insulin and cancer-induced HIF-1 cooperate to provide pancreatic cancer cells with a survival advantage. However, additional studies are required to elucidate the mechanisms underlying this cooperation.

\section{Acknowledgements}

The authors of the present study thank Dr Shasha Li from Tianjin Medical University for her technical assistance and the 
Qian-Ren Program of the Tianjin Municipal Government for their financial support (grant no. 116001-20100004).

\section{References}

1. Semenza GL and Wang GL: A nuclear factor induced by hypoxia via de novo protein synthesis binds to the human erythropoietin gene enhancer at a site required for transcriptional activation. Mol Cell Biol 12: 5447-5454, 1992.

2. SalcedaS andCaroJ:Hypoxia-inducible factor 1alpha(HIF-1alpha) protein is rapidly degraded by the ubiquitin-proteasome system under normoxic conditions. Its stabilization by hypoxia depends on redox-induced changes. J Biol Chem 272: 22642-22647, 1997.

3. Lee JW, Bae SH, Jeong JW, Kim SH and Kim KW: Hypoxia-inducible factor (HIF-1)alpha: Its protein stability and biological functions. Exp Mol Med 36: 1-12, 2004.

4. Koong AC, Mehta VK, Le QT, et al: Pancreatic tumors show high levels of hypoxia. Int J Radiat Oncol Biol Phys 48: 919-922, 2000

5. Zhong H, De Marzo AM, Laughner E, et al: Overexpression of hypoxia-inducible factor lalpha in common human cancers and their metastases. Cancer Res 59: 5830-5835, 1999.

6. Fukuda R, Hirota K, Fan F, Jung YD, Ellis LM and Semenza GL: Insulin-like growth factor 1 induces hypoxia-inducible factor 1-mediated vascular endothelial growth factor expression, which is dependent on MAP kinase and phosphatidylinositol 3-kinase signaling in colon cancer cells. J Biol Chem 277: 38205-38211, 2002.

7. Wang F, Li SS, Segersvärd R, Strömmer L, Sundqvist KG, Holgersson J and Permert J: Hypoxia inducible factor-1 mediates effects of insulin on pancreatic cancer cells and disturbs host energy homeostasis. Am J Pathol 170: 469-477, 2007.

8. Funasaka T, Yanagawa T, Hogan V and Raz A: Regulation of phosphoglucose isomerase/autocrine motility factor expression by hypoxia. FASEB J 19: 1422-1430, 2005.

9. Warburg O: On the origin of cancer cells. Science 123 309-314, 1956

10. Lyshchik A, Higashi T, Hara T, et al: Expression of glucose transporter-1, hexokinase-II, proliferating cell nuclear antigen and survival of patients with pancreatic cancer. Cancer Invest 25 : 154-162, 2007.

11. Nakagawa A, Samols E and Stagner JI: Exocrine interstitial insulin and somatostatin in the perfused dog pancreas. Am J Physiol 264: G728-G734, 1993.
12. Gallagher EJ and LeRoith D: The proliferating role of insulin and insulin-like growth factors in cancer. Trends Endocrinol Metab 21: 610-618, 2010.

13. Trajkovic-Arsic M, Kalideris E and Siveke JT: The role of insulin and IGF system in pancreatic cancer. J Mol Endocrinol 50: R67-R74, 2013.

14. Wang F, Larsson J, Adrian TE, Gasslander T and Permert J: In vitro influences between pancreatic adenocarcinoma cells and pancreatic islets. J Surg Res 79: 13-19, 1998.

15. Ding XZ, Fehsenfeld DM, Murphy LO, Permert J and Adrian TE: Physiological concentrations of insulin augment pancreatic cancer cell proliferation and glucose utilization by activating MAP kinase, PI3 kinase and enhancing GLUT-1 expression. Pancreas 21: 310-320, 2000.

16. Liu Z, Jia X, Duan Y, Xiao H, Sundqvist KG, Permert J and Wang F: Excess glucose induces hypoxia-inducible factor-1a in pancreatic cancer cells and stimulates glucose metabolism and cell migration. Cancer Biol Ther 14: 428-435, 2013

17. Xiao H, Li S, Zhang D, Liu T, Yu M and Wang F: Separate and concurrent use of 2-deoxy-D-glucose and 3-bromopyruvate in pancreatic cancer cells. Oncol Rep 29: 329-334, 2013.

18. Graham ML, Janecek JL, Kittredge JA, Hering BJ and Schuurman HJ: The streptozotocin-induced diabetic nude mouse model: Differences between animals from different sources. Comp Med 61: 356-360, 2011.

19. Wang F, Larsson J, Abdiu A, Gasslander T, Westermark P, Adrian TE and Permert J: Dissociated secretion of islet amyloid polypeptide and insulin in serum-free culture media conditioned by human pancreatic adenocarcinoma cell lines. Int J Pancreatol 21: 157-164, 1997.

20. Wang F, Kumagai-Braesch M, Herrington MK, Larsson J and Permert J: Increased lipid metabolism and cell turnover of $\mathrm{MiaPaCa} 2$ cells induced by high fat diet in an orthotopic system. Metabolism 58: 1131-1136, 2009.

21. Asano N, Manabe T, Imanishi K and Tobe T: Changes of A $\mathrm{B}$ and D cells in Langerhans islets in pancreatic cancers of hamsters. Nihon Geka Hokan 60: 233-242, 1991.

22. Torosian MH, Bartlett DL, Chatzidakis C and Stein TP: Effect of tumor burden on futile glucose and lipid cycling in tumor-bearing animals. J Surg Res 55: 68-73, 1993.

23. Lundholm K, Edström S, Karlberg I, Ekman L and Scherstén T: Glucose turnover, gluconeogenesis from glycerol, and estimation of net glucose cycling in cancer patients. Cancer 50: 1142-1150, 1982. 